\title{
Perilla Mosaic Virus Is a Highly Divergent Emaravirus Transmitted by Shevtchenkella sp. (Acari: Eriophyidae)
}

\author{
Kenji Kubota, ${ }^{1, \dagger}$ Tomio Usugi, ${ }^{1}$ Yasuhiro Tomitaka, ${ }^{2}$ Yoshifumi Shimomoto, ${ }^{3}$ Shigeharu Takeuchi, ${ }^{3}$ Fujio Kadono, ${ }^{4}$ \\ Hironobu Yanagisawa, ${ }^{1}$ Yuya Chiaki, ${ }^{1}$ and Shinya Tsuda ${ }^{1}$ \\ ${ }^{1}$ Central Region Agricultural Research Center, NARO, Kannondai, Tsukuba, Ibaraki 305-8666, Japan \\ ${ }^{2}$ Kyushu Okinawa Agricultural Research Center, NARO, Suya, Koshi, Kumamoto 861-1192, Japan \\ ${ }^{3}$ Kochi Agricultural Research Center, Hataeda, Nankoku, Kochi 783-0023, Japan \\ ${ }^{4}$ Department of Clinical Plant Science, Faculty of Bioscience and Applied Chemistry, Hosei University, Kajino-cho, Koganei, Tokyo 184- \\ 8584, Japan \\ Accepted for publication 18 March 2020.
}

\begin{abstract}
Shiso (Perilla frutescens var. crispa) is widely grown as an important vegetable or herb crop in Japan. Beginning around the year 2000 , occurrences of severe mosaic symptoms on shiso were documented and gradually spread across Kochi Prefecture, one of four major shiso production areas in Japan. Next generation sequencing and cloning indicated the presence of a previously unknown virus related to the members of the genus Emaravirus, for which we proposed the name Perilla mosaic virus (PerMV). The genome of PerMV consists of 10 RNA segments, each encoding a single protein in the negative-sense orientation. Of these proteins, P1, P2, P3a, P3b, P4, and P5 show amino acid sequence similarities with those of known emaraviruses, whereas no similarities were found in P6a, P6b, P6c, and P7. Characteristics of the RNA segments as well as phylogenetic analysis of P1 to P4
\end{abstract}

ABSTRACT indicate that PerMV is a distinct and highly divergent emaravirus. Electron microscopy observations and protein analyses corresponded to presence of an emaravirus. Transmission experiments demonstrated that an eriophyid mite, Shevtchenkella sp. (family Eriophyidae), transmits PerMV with a minimum 30-min acquisition access period. Only plants belonging to the genus Perilla tested positive for PerMV, and the plant-virus-vector interactions were evaluated. The nucleotide sequences reported here are available in the DDBJ/ENA/ GenBank databases under accession numbers LC496090 to LC496099.

Keywords: emaravirus, Perilla mosaic virus, phylogenetic analysis, Perilla frutescens, shiso, virology
The genus Emaravirus, the sole genus in the family Fimoviridae, order Bunyavirales, encompasses plant viruses with multipartite, negative-sense single-stranded RNA genomes (Elbeaino et al. 2018). Emaraviruses are disease causal agents of important crops including cereals, fruits, and flowering trees worldwide (MielkeEhret and Mühlbach 2012). The genus includes nine established species: Actinidia chlorotic ringspot-associated virus (AcCRaV) (Zheng et al. 2017), European mountain ash ringspot-associated virus (EMARaV, the type species of the genus Emaravirus) (Mielke-Ehret and Mühlbach 2007; von Bargen et al. 2019), Fig mosaic virus (FMV) (Elbeaino et al. 2009a, b; Ishikawa et al.

†Corresponding author: K. Kubota; kubotak@affrc.go.jp

Current address for Y. Chiaki: Grape and Persimmon Research Station, Institute of Fruit tree and Tea Science, NARO, Akitsu, Higashi-Hiroshima, Hiroshima 7392494, Japan.

Current address for S. Tsuda: Department of Clinical Plant Science, Faculty of Bioscience and Applied Chemistry, Hosei University, Kajino-cho, Koganei, Tokyo 184-8584, Japan.

Funding: This study was supported by a Grant-in-Aid for "Development of Practical Technologies to Implement New Agricultural, Forestry, and Fishery Policies" administered by the Ministry of Agriculture, Forestry, and Fisheries of Japan (27001C) and the Fund for Objective Basic Research provided by CARC/ NARO.

*The $e$-Xtra logo stands for "electronic extra" and indicates that seven supplementary figures and five supplementary tables are published online.

The author(s) declare no conflict of interest.

(C) 2020 The American Phytopathological Society 2012a), High Plains wheat mosaic virus (HPWMoV) (Tatineni et al. 2014), Pigeon pea sterility mosaic virus 1 (PPSMV-1) (Elbeaino et al. 2014), Pigeon pea sterility mosaic virus 2 (PPSMV-2) (Elbeaino et al. 2015), Raspberry leaf blotch virus (RLBV) (McGavin et al. 2012), Redbud yellow ringspot-associated virus (RYRSaV) (Di Bello et al. 2016), and Rose rosette virus (RRV) (Di Bello et al. 2015; Laney et al. 2011). In addition, potential new emaraviruses have been reported: Actinidia emaravirus-2 (AcEV-2) (Wang et al. 2020), blackberry leaf mottle-associated virus (BLMaV) (Hassan et al. 2017), blue palo verde broom virus (PVBV) (Ilyas et al. 2018), jujube yellow mottle-associated virus (JYMaV) (Yang et al. 2019), Pistacia virus B (PiVB) (Buzkan et al. 2019), and ti ringspotassociated virus (TiRSaV) (Olmedo-Velarde et al. 2019).

Electron microscopy observations of emaravirus infected plant tissues have shown the presence of spherical structures of 80 to $200 \mathrm{~nm}$ in diameter with a double layer of membranes, called double membrane bodies (DMBs). In some emaraviruses, filamentous virus particles consisting of RNA and nucleocapsid proteins (NPs) were also obtained from the infected tissues (Mielke-Ehret and Mühlbach 2012).

The genomes of emaraviruses consist of five to nine RNA segments, depending on species. Each segment shows partial complementarity between $\sim 20$ nucleotides (nt) of the $5^{\prime}$ - and $3^{\prime}$ terminal sequence to form a panhandle structure, and the $5^{\prime}$ - and $3^{\prime}$ terminal $13 \mathrm{nt}$ are highly conserved among segments of a species. Each RNA segment is of negative polarity and contains a single open reading frame (ORF) in the viral-complementary RNA strand. RNA1 of emaraviruses are 7 to $8 \mathrm{~kb}$ in length, which encodes $\mathrm{P} 1$, a putative RNA-dependent RNA polymerase (RdRp) of the estimated molecular mass of 264 to $269 \mathrm{kDa}$. P1 contains motifs A, B, C, D, E, 
and $\mathrm{F}$, which are conserved among viruses in the order Bunyavirales (Amroun et al. 2017; Kumar et al. 2017). RNA2 encodes P2, a putative glycoprotein precursor (GP) whose molecular mass is 73 to $77 \mathrm{kDa}$. RNA3 encodes P3, a putative NP of 32 to $35 \mathrm{kDa}$. RNA4 encodes P4, a movement protein (MP) (Elbeaino et al. 2018). These four "canonical" proteins have been found in all emaraviruses. However, most of the other proteins (P5 to P8) show low sequence similarities to any other functionally identified proteins, making their functions elusive. Moreover, the P7 and P8 proteins of HPWMoV have been shown to exert RNA silencing suppressor activities (Gupta et al. 2018, 2019). Another unique feature of emaravirus genomes is the presence of redundant RNA segments encoding proteins with sequence similarities among the amino acid sequences. For example, HPWMoV and PiVB harbor two variants of RNA3, which encode homologous NPs, and have an amino acid sequence identity of 88.9 and 78.6\%, respectively (Buzkan et al. 2019; Tatineni et al. 2014). The P6, P7, and P8 proteins of RLBValso share sequence identities of 30 to $43 \%$ at the N-terminal regions (Lu et al. 2015).

Each emaravirus is transmitted by a specific Eriophyid mite (Acari: Eriophyidae). The vector species are Aceria ficus for FMV (Flock and Wallace 1955; Martelli et al. 1993), Aceria tosichella for HPWMoV (Seifers et al. 1997; Skare et al. 2003), Aceria cajani for PPSMV (Kulkarni et al. 2002; Seth 1962), Phyllocoptes gracilis for RLBV (Gordon and Taylor 1976), and Phyllocoptes fructiphilus for RRV (Amrine et al. 1988). Accumulation of NP of EMARaV in a putative vector, pear bristle mite (Phytoptus pyri), has been reported (Mielke-Ehret et al. 2010). Vector mite species, however, have not been identified for many emaraviruses. Furthermore, information on the mode of transmission is limited (Kulkarni et al. 2002), and its mechanism is not yet well understood.

Perilla frutescens L., a plant species in the family Lamiaceae, is native to a region between the Himalaya and Southern China. Perilla frutescens includes Perilla frutescens var. crispa (known as "shiso") and Perilla frutescens var. frutescens ("egoma"). Shiso has two major varieties, the green-leaved and purple-leaved. In Japan, green-leaved shiso leaves are widely used as a vegetable or herb in traditional Japanese dishes and produced year-round under greenhouse cultivation. The net production in 2016 was 5,246 tonnes, and the major production areas include Aichi, Ibaraki, Oita, and Kochi Prefectures (Ministry of Agriculture, Forestry and Fisheries of Japan 2019). Purple-leaved shiso is mainly used as a coloring agent of pickles and is grown in open fields. Egoma has also long been cultivated as an oil crop. The other three species of Perilla, Perilla citriodora, Perilla hirtella, and Perilla setoyensis are not cultivated but grow wild in Japan (Ito and Honda 1996).

Around the year 2000, emergence of severe mosaic symptoms was noted on leaves of cultivated green shiso in Nankoku City, Kochi Prefecture, Japan (Kubota 2017) (Supplementary Fig. S1A); moreover, limited occurrences of the disease, albeit less severe, have been noted for nearly 40 years in Aichi Prefecture (Kubota 2017). The symptoms included chlorosis or yellowing of leaves and leaf malformations. Because color intensity and leaf shape are the most important traits for marketability of greenleaved shiso, occurrence of the disease resulted in considerable or complete yield losses. The symptoms spread gradually in the area, and the incidence rate of symptomatic plants reached nearly $100 \%$ in some greenhouses. In the year-round cultivation of shiso, occurrences of the mosaic disease peak from summer to autumn (Horikawa et al. 2018). Although a potyvirus, Perilla mottle virus, that infects shiso and causes mosaic symptoms, and is transmitted by the aphid Myzus persicae, has been reported (Lee et al. 1980), the newly emerging mosaic disease in Kochi was different since it neither had potyvirus-like filamentous particles nor was aphid transmitted, as described below. Furthermore, in our previous studies, the presence of a novel RNA virus, whose partial nucleotide sequence showed similarities with RNA4 of the other emaraviruses, has been identified and specifically detected from mosaic-displaying shiso. The virus was designated as Perilla mosaic virus (PerMV) (Kubota 2017; Suzuki et al. 2019). Subsequently, we tried to identify and characterize the new emara-like virus through cloning of double-stranded RNA (dsRNA) and next generation sequencing (NGS) techniques.

Along with this study, a new species of eriophyid mite, tentatively named perilla rust mite (PRM), Shevtchenkella sp. (Supplementary Fig. S1B), was discovered on shiso in Chiba Prefecture in 2013 and was the first species of the genus Shevtchenkella found in Japan. PRM causes rust symptoms on shiso when it proliferates at a high density (Suzuki et al. 2018; Takei et al. 2019). PRM was also found in greenhouses where mosaic disease occurred in Kochi. Our preliminary investigations suggested that the spread of the mosaic disease was correlated with the presence of the PRM. Incidence of the mosaic disease as well as PerMV RNA sequence and the PRM have been confirmed on cultivated shiso not only in Kochi but also in Aichi, Ibaraki, and Oita Prefectures, which are also major shiso production areas in Japan (Kubota 2017; Tsunekawa et al. 2019).

We report here the complete nucleotide sequence of PerMV and its phylogenetic relationships with the other emaraviruses showing that PerMV is a distinct and highly divergent emaravirus. In addition, we describe biological properties of PerMV including arthropod vector transmission and host range, which are important to understand in order to design an efficient management strategy of the disease.

\section{MATERIALS AND METHODS}

Collection and maintenance of shiso plants with the mosaic symptoms. Cultivated shiso plants (cultivar NankokuZairai) with typical mosaic symptoms were collected from a greenhouse in Nankoku City, Kochi Prefecture, Japan, in 2011. Individual plants were transplanted into $15 \mathrm{~cm}$ pots and maintained in a glasshouse. After infection by PerMV was confirmed by RTPCR as described below, virus-infected seedlings were propagated by cuttings and new shiso plants were infected by periodic transmission of the virus via acquisition and transmission feeding by PRM, as described below. One of the collected isolates, designated as Kochi_Nankoku_2011, was used for further analysis.

Evaluation of PerMV infection by RT-PCR. Total RNA was extracted from leaf tissue using an RNeasy Plant Mini Kit (Qiagen, Hilden, Germany). RT-PCR was performed with PerMV specific primers Shiso-23F3 and Shiso-23R3 (Supplementary Table S1) using a PrimeScript One Step RT-PCR Kit Ver. 2 (Takara Bio, Shiga, Japan). Thermal cycling consisted of reverse-transcription at $50^{\circ} \mathrm{C}$ for $30 \mathrm{~min}$, inactivation of reverse transcription at $94^{\circ} \mathrm{C}$ for $2 \mathrm{~min}$, followed by PCR amplification for 35 cycles at $94^{\circ} \mathrm{C}$ for $30 \mathrm{~s}$, at $55^{\circ} \mathrm{C}$ for $30 \mathrm{~s}$, and at $72^{\circ} \mathrm{C}$ for $15 \mathrm{~s}$. The RT-PCR product was separated by $2 \%$ agarose gel electrophoresis.

Sequence analyses of PerMV. Total RNA of infected shiso leaves was extracted using TRIzol (ThermoFisher Scientific, Tokyo, Japan). Partial viral genome sequences were obtained by dsRNA extraction, cloning, and sequencing, as described previously (Kobayashi et al. 2009; Shimomoto et al. 2014). Nucleotide sequences obtained were analyzed using the Blastx program (Altschul et al. 1997). For NGS, total RNA was extracted from shiso leaves infected with Kochi_Nankoku_2011 using the rapid CTAB method (Gambino et al. 2008) and sent to BGI Japan (Kobe, Japan). After removal of ribosomal RNAs by Ribo-Zero Magnetic Kit (Illumina, San Diego, CA, U.S.A.) and library construction which included fragmentation of RNA, cDNA synthesis, and PCR amplification, sequencing was carried out using a NovaSeq 6000 sequencer (Illumina) with paired-end $150 \mathrm{nt}$ sequencing reads. De novo assembly was conducted using CLC Genomics Workbench 11.0 Software (Qiagen), with minimum length of $500 \mathrm{bp}$. To find potential emaravirus RNA segments among the contigs, Blastx searches were performed with amino acid sequences of all proteins 
encoded by emaraviruses deposited in GenBank as of January 2019. To determine an accurate, complete nucleotide sequence of each of the candidate sequences, 5' - and 3'-rapid amplification of cDNA ends (RACE) were performed using 5' - and 3'-full RACE core set, respectively (TakaraBio), and the primers shown in Supplementary Table S1. For the $3^{\prime}$-RACE, a poly(A) tail was added to the $3^{\prime}$ end using poly(A) polymerase (New England Biolabs, Ipswich, MA, U.S.A.). The 5'- and $3^{\prime}$-RACE products were cloned into the pGEM-T easy vector (Promega, Madison, WI, U.S.A.).

Understanding that the $5^{\prime}$ and $3^{\prime}$ terminal nucleotide sequences of RNA segments within an emaravirus species are highly conserved, we thoroughly investigated the other RNA segments of PerMV. RT-PCR amplification was carried out utilizing the conserved sequences as described previously (Ishikawa et al. 2012a). In brief, cDNAs were synthesized with the total RNA extracted from shiso leaves infected with Kochi_Nankoku_2011 as templates by PrimeScript Reverse Transcriptase (TakaraBio) with primers PerMV-5' ter-11mer-fw and PerMV-3' ter-11mer-rv (Supplementary Table S1) following the manufacturer's instructions with the modification that the first denaturation was performed at $98^{\circ} \mathrm{C}$ for 2 min for complete denaturation of the $5^{\prime}$ - and $3^{\prime}$-termini with near perfect complementarity. PCR amplification was performed with primers BamHI-PerMV-5'ter-11mer-fw and BamHI-PerMV-3'ter11mer-rv (Supplementary Table S1) using Tks Gflex DNA polymerase (TakaraBio). The thermal cycling procedure was as follows: $94^{\circ} \mathrm{C}$ for $1 \mathrm{~min}, 5$ cycles of $98^{\circ} \mathrm{C}$ for $10 \mathrm{~s}, 25^{\circ} \mathrm{C}$ for $15 \mathrm{~s}$, $68^{\circ} \mathrm{C}$ for $1.5 \mathrm{~min}$, followed by 35 cycles of $98^{\circ} \mathrm{C}$ for $10 \mathrm{~s}, 55^{\circ} \mathrm{C}$ for $10 \mathrm{~s}$, and $68^{\circ} \mathrm{C}$ for $1.5 \mathrm{~min}$. The PCR products were digested with Sau3AI and cloned into the BamHI site of pUC19. Sequences of the cloned fragments were determined with M13 primers. The complete nucleotide sequence of each segment was confirmed by $5^{\prime}$ - and $3^{\prime}$-RACE as described above as well as by direct sequencing of the appropriately amplified RT-PCR products using an ABI 3100xl Genetic Analyzer (Applied Biosystems, Waltham, MA, U.S.A.). The sequences obtained were assembled by CodonCode Aligner software (CodonCode Corporation, Centerville, MA). The deduced amino acid sequences encoded by the identified RNA segments were analyzed by Pfam search (Finn et al. 2014). Amino acid sequence identities of proteins encoded by PerMV RNAs and the other emaraviruses were calculated using the SDTv1.2 program (Muhire et al. 2014) with the MAFFT option.

For phylogenetic analysis, the amino acid sequences of PerMV, the other emaraviruses, and selected representative viruses in the order Bunyavirales obtained from the NCBI database were used. The sequences were aligned using the MAFFT program Ver. 7 (Katoh and Standley 2013) with default settings. Phylogenetic trees were reconstructed using the neighbor-joining (NJ) method incorporated into MEGA 7 software (Kumar et al. 2016). The NJ analyses were conducted with the Poisson correction and pairwise gap deletion. The phylogeny was tested by performing 1,000 bootstrap pseudo-replicates. Protein analysis for prediction of protein transmembrane domains was conducted using the TMHMM program (Krogh et al. 2001). Prediction of $N$-glycosylation sites and signal peptide was conducted using the NetNGlyc 1.0 server (http://www.cbs.dtu.dk/services/NetNGlyc/). Prediction of cleavage sites was conducted using SignalP 3.0 (Bendtsen et al. 2004). Coiled coil regions were predicted by COILS (Lupas et al. 1991). Multiple sequence alignment for the P4 proteins of emaraviruses was constructed by Promals (Pei and Grishin 2007). Pairwise amino acid sequence alignment of proteins was created by the EMBOSS Needle (Madeira et al. 2019).

Virion purification, electron microscopy, and protein analysis. Leaves showing typical mosaic symptoms were collected from a greenhouse in Nankoku City. Sixty grams of leaf tissue was added to $300 \mathrm{ml}$ of TM buffer $(50 \mathrm{mM}$ Tris- $\mathrm{HCl}[\mathrm{pH} 8.0]$ supplemented with $0.1 \%$ 2-mercapthoethanol) then macerated by a homogenizer. The homogenate was filtered through two layers of cheesecloth, and the filtrate was added to $15 \mathrm{ml}$ of tetrachloromethane and then mixed by a homogenizer for $1 \mathrm{~min}$. After debris removal by centrifugation at $6,000 \times g$ for $15 \mathrm{~min}$ at $4^{\circ} \mathrm{C}$, the supernatant was added drop-wise to $3 \mathrm{ml}$ of Triton X-100 and stirred for $20 \mathrm{~min}$ on ice. Subsequently, the mixture was separated by ultracentrifugation at $48,700 \times g$ for $30 \mathrm{~min}$ at $4^{\circ} \mathrm{C}$ with a CP 70MX ultracentrifuge (Koki Holdings, Tokyo, Japan) and P45AT angle rotor. The resulting supernatant was centrifuged at $141,900 \times g$ for $90 \mathrm{~min}$. The pellet was dissolved in $6 \mathrm{ml}$ of TM buffer, and the debris was removed by centrifugation at $9,850 \times g$ for $15 \mathrm{~min}$. The supernatant was again centrifuged at $148,000 \times g$ for $1 \mathrm{~h}$, and its pellet was dissolved in $2 \mathrm{ml}$ of TM buffer. To further purify the virion, the supernatant was separated by density gradient centrifugation with four layers of caesium sulfate $(10,20$, 30 , and $40 \%$ [wt/wt], from top to bottom) at 218,000 $\times g$ for $18 \mathrm{~h}$ with a P40ST swing rotor, and a turbid fraction containing virions were collected by glass pipette. The fraction was diluted with five times the volume of TM buffer, and then the virions were pelleted by ultracentrifugation at $148,000 \times g$ for $1 \mathrm{~h}$ and finally dissolved in $200 \mu \mathrm{l}$ of $50 \mathrm{mM}$ Tris- $\mathrm{HCl}$ ( $\mathrm{pH} \mathrm{8.0)}$ ). The purified virions were stored at $-80^{\circ} \mathrm{C}$ until use.

The virion was stained with $2 \%$ uranyl acetate and observed under a transmission electron microscopy JEM1230 (JEOL, Tokyo, Japan). The virion sample described above was analyzed by sodium dodecyl sulfate-15\% polyacrylamide gel electrophoresis (SDS-15\% PAGE) and Coomassie brilliant blue staining. For immunoblot analysis, leaf tissue of mosaic leaves infected with the isolate Kochi_ Nankoku_2011 were homogenized in $100 \mathrm{mM}$ Tris-HCl (pH 6.8) and $4 \%$ SDS-200 mM dithiothreitol. After debris were removed by centrifugation, the supernatant was mixed with the same buffer containing $4 \%$ glycerol and $0.02 \%$ bromo phenol blue and treated at $98^{\circ} \mathrm{C}$ for $3 \mathrm{~min}$. The total soluble proteins were separated by SDS-PAGE with a 5 to $20 \%$ gradient polyacrylamide gel (ATTO, Tokyo, Japan) and electro-transferred onto a polyvinylidene difluoride membrane (ATTO). Antisera against PerMV NPs (i.e., $\mathrm{P} 3 \mathrm{a}$ and $\mathrm{P} 3 \mathrm{~b}$, described below) were produced by immunizing a rabbit with a synthesized polypeptide CYEGLLETKIESQSRDME (amino acid position 55 to 71 of PerMV P3a and P3b, a cysteine residue was added at the $\mathrm{N}$ terminus). The membrane was treated with anti-PerMV NPs antibody or antirabbit immunoglobulin G, alkaline phosphatase conjugated, as primary and secondary antibodies, and immunoreactive bands were detected by NBT/BCIP Stock Solution (Roche Diagnostics, Mannheim, Germany) following the manufacturer's instructions.

Transmission experiment. PRMs were collected from shiso plants exhibiting mosaic symptoms in a greenhouse in Nankoku City (Takei et al. 2019). The mites were maintained on shiso grown in a $9 \mathrm{~cm}$ pot placed in an insect-proof cage with $0.4-\mathrm{mm}$ mesh, in a growth chamber set at $28^{\circ} \mathrm{C}$ with a 16 -h light $/ 8$-h dark photoperiod. Under a stereomicroscope, 20 mites were transferred monthly with a fine brush from an infested plant showing mosaic and rust symptoms to a new, healthy shiso to maintain a PerMV-viruliferous population. Eggs laid by the PerMV-viruliferous population mites were used to establish a PerMV-nonviruliferous mite population through several passages on healthy shiso leaflets kept in a growth chamber. After 21 days, newly emerged eggs would be transferred to a new leaflet. The passaging was repeated three times, and the resulting nonviruliferous population was maintained on healthy shiso plants as described above. For both populations, presence and absence of PerMV were periodically confirmed by observation for mosaic symptoms on the infected plants and detection of PerMV by RT-PCR with Shiso-23F3 and Shiso-23R3 primers as described above.

For the transmission experiments of PerMV, nonviruliferous adult PRMs were transferred onto either a healthy or symptomatic shiso leaflet for acquisition access periods (AAPs) of 6, 12, and 20 days. For inoculation phase, groups of 10 PRMs were transferred onto the first or second true leaf of young shiso seedlings, and inoculated plants were maintained in the growth chamber. After an 
inoculation access period (IAP) of about 21 days, inoculated plants were observed for mosaic symptoms and tested for infection with PerMV by RT-PCR of a newly developed upper leaf. To avoid mutual contamination of the PRMs, experiments with the PerMVacquired and the nonacquired mites were conducted in separate chambers.

To test the transmissibility of PerMV by other arthropod species observed in shiso greenhouses, adult individuals of each species were collected and were reared on a PerMV-infected shiso plants for 7 to 14 days. Arthropods were then transferred onto a healthy shiso seedling with two to three true opposite leaves. After 3 days of IAP, the arthropods were eliminated with a pesticide spray and symptom development was observed until 28 days after inoculation. Ten arthropod species were tested, which were Bemisia tabaci (Aleyrodidae), Trialeurodes vaporariorum (Aleyrodidae), Aphis egomae (Aphididae), Aphis gossypii (Aphididae), Myzus persicae (Aphididae), Hishimonus sellatus (Cicadellidae), Macrosteles striifrons (Cicadellidae), Phenacoccus madeirensis (Pseudococcidae), Polyphagotarsonemus latus (Tarsonemidae), and Echinothrips americanus (Thripidae).

Host range analysis. Two methods were employed to inoculate plants with PerMV. For inoculation by PRM, 10 to 20 PerMV-viruliferous PRM individuals were transferred on young seedlings of target plants, which were Perilla frutescens var. crispa, Perilla frutescens var. frutescens, Perilla citriodora, Perilla hirtella, Perilla setoyensis, Ajuga decumbens, Clinopodium gracile, and Lamium amplexicaule, of the family Lamiaceae, and Nicotiana benthamiana of the family Solanaceae. Leaves of $N$. benthamiana were washed with water to remove sticky substances prior to infestation. For mechanical inoculation, a PerMV-infected mosaic leaf was homogenized with mortar and pestle in $50 \mathrm{mM}$ Tris- $\mathrm{HCl}(\mathrm{pH} 8.0)$ supplemented with $0.1 \%$ 2mercapthoethanol. Expanded leaves of $N$. benthamiana were then mechanically inoculated with the homogenate using Carborundum powder. The inoculated plants were maintained in a glasshouse and observed for symptoms and tested for PerMV infection by RT-PCR carried out as described above. Seeds of Perilla frutescens, Perilla hirtella, Perilla setoyensis, and Perilla citriodora were obtained from Genebank Project, NARO (https://www.gene.affrc.go.jp/ index_en.php). Seeds of Ajuga decumbens, Clinopodium gracile, and Lamium amplexicaule were supplied by Motoaki Asai (NARO).

\section{RESULTS}

Surveillance of unknown RNA virus by cloning of dsRNA. Among 96 sequences of dsRNA cloned, one clone contained a 330-nt sequence that encoded a partial ORF with amino acid sequence similarity to the RdRp of EMARaV (28 and $47 \%$ sequence identity and similarity in 109 amino acids, respectively). The full-length nucleotide sequence determined by NGS and cloning in combination with $5^{\prime}$ - and $3^{\prime}$-RACE was $\sim 7.3 \mathrm{~kb}$, and its complementary strand contained an ORF encoding a protein homologous to RdRp of emaraviruses. To obtain the complete nucleotide sequences of the other RNA segments expected, NGS and RT-PCR amplification of full-length RNA segments using conserved terminal sequences were conducted.

Genome organization and proteins of PerMV. Using NGS followed by de novo assembly, a total of 31,523 contigs (maximum length $13,133 \mathrm{nt}$, minimum length $500 \mathrm{nt}$, and mean length 1,040 nt) were generated from a dataset consisting of 33,479,404 reads $(5,021,910,600 \mathrm{nt}$ in total) (Supplementary Table S2). Blastx searches identified six possible emaravirus-like segments (RNA1, RNA2, RNA3a, RNA3b, RNA4, and RNA5) encoding proteins with sequence similarities to emaravirus proteins. Determination of the complete nucleotide sequences by $5^{\prime}$ - and $3^{\prime}$-RACE revealed that all of them harbored the conserved 11- and 12-nt sequences at the $5^{\prime}$ - and $3^{\prime}$-termini, respectively (5'-AGUAGUUAUCU...... AGCAAAACUACU-3') (Supplementary Fig. S2), as with the other emaraviruses. To identify other possible segments, RT-PCR products using the conserved 11-nt terminal sequences were cloned and sequenced. Based on the following common features among emaravirus segments: (i) one protein encoded on the complementary strand, (ii) conserved 11- and 12-nt sequence at the $5^{\prime}$ - and $3^{\prime}$-termini, and (iii) near perfect complementarity between $\sim 20$-nt sequences at the $5^{\prime}$ - and $3^{\prime}$-termini, four possible segments (RNA6a, RNA6b, RNA6c, and RNA7) were identified. Their complete nucleotide sequences were confirmed by $5^{\prime}$ - and 3 '-RACE followed by mapping the NGS reads to the obtained sequences of PerMV RNA segments (Supplementary Table S2). In total, 10 RNA segments were identified (Fig. 1, Supplementary Table S3). All of them showed near perfect complementarity between $\sim 20$-nt sequences at the $5^{\prime}$ - and $3^{\prime}$-termini (Supplementary Fig. S2). No or all amplification products from RT-PCR were obtained from healthy or PerMV-infected shiso, respectively, with primers specific to each PerMV segment shown in Supplementary Table S1 (Supplementary Fig. S3), making these segment sequences most likely derived from the virus and not from host genes.

RNA1 was 7,291 nt in length and contained an ORF (nucleotide positions 7212 to 205) that encoded P1, a putative RdRp of 2,335 amino acids with a predicted molecular mass of $272.9 \mathrm{kDa}$. Pairwise comparisons of the deduced amino acid sequence showed similarities between PerMV P1 and RdRps of other emaraviruses, ranging from $31.2 \%$ (RLBV) to $33.0 \%$ (AcCRaV) (Supplementary Table S4). Motifs A, B, C, D, E, and F, which are conserved in RdRps of emaraviruses and viruses of the family Bunyaviridae (Amroun et al. 2017), were also detected in P1 (Supplementary Fig. S4A).

RNA2 was 2,092 nt in length and contained an ORF (nucleotide positions 2038 to 119) that encodes P2, a putative GP of 639 amino acids with a predicted molecular mass of $73.2 \mathrm{kDa}$. It showed 21.9 to $26.9 \%$ identity at the amino acid level with GPs of the other

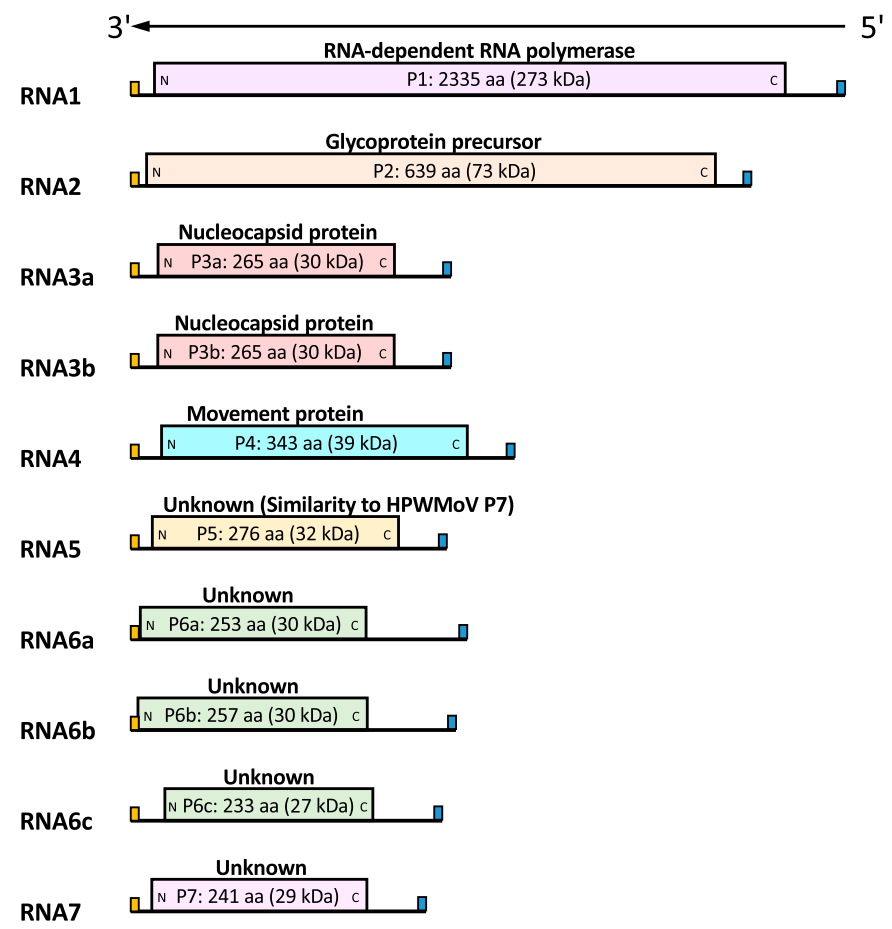

Fig. 1. Schematic representation of the organization of the Perilla mosaic virus (PerMV) genomic RNAs. Open reading frames are shown by rectangles and those with amino acid sequence similarities to one another are colored the same. The 11- and 12-nucleotide conserved sequences at the 5'- and $33^{\prime}$-terminal on each segment are represented by blue and yellow boxes, respectively. Drawings are not to scale. 
emaraviruses (Supplementary Table S4). P2 contained a phlebovirus glycoprotein motif $\left(\mathrm{G}_{493} \mathrm{CYDCQPG}\right)$, which is conserved in $\mathrm{P} 2$ of known emaraviruses (Supplementary Fig. S4). The presence of four transmembrane helices (at amino acid positions 7 to 25, 114 to 132,182 to 204 , and 601 to 619 ) and four $N$-glycosylation sites $\left(\mathrm{N}_{198} \mathrm{CSP}, \mathrm{N}_{285} \mathrm{HTG}, \mathrm{N}_{452} \mathrm{RTI}\right.$, and $\mathrm{N}_{581} \mathrm{FSF}$ ) were predicted. Additionally, two cleavage sites $\left(\mathrm{ML}_{21} \downarrow_{22} \mathrm{HK}\right.$ and $\left.\mathrm{NC}_{199} \downarrow_{200} \mathrm{SP}\right)$ were predicted, which would yield three cleavage products of $2.46 \mathrm{kDa}(\mathrm{Gs}), 20.58 \mathrm{kDa}(\mathrm{Gn})$, and $50.20 \mathrm{kDa}(\mathrm{Gc})$ (Supplementary Fig. S4B).

Similar to that reported with HPWMoV and PiVB (Buzkan et al. 2019; Tatineni et al. 2014), PerMV harbored two variants of RNA3, namely RNA3a of $1,080 \mathrm{nt}$ in length and RNA3b of $1,078 \mathrm{nt}$. RNA3b is 1-nt shorter in its $5^{\prime}$ - and $3^{\prime}$-untranslated regions compared with RNA3a (Fig. 1 and Supplementary Table S3). RNA3a contains an ORF encoding P3a of 265 amino acids with a predicted molecular mass of $30.1 \mathrm{kDa}$, whereas RNA3b encodes $\mathrm{P} 3 \mathrm{~b}$, which is 265 amino acids with a predicted molecular mass of $30.0 \mathrm{kDa}$. P3a and P3b shared $83.0 \%$ amino acid sequence identity between them, and they showed 19.9 to $28.6 \%$ amino acid sequence identities with putative NPs of the other emaraviruses (Supplementary Table S4). Among the three well conserved motifs of P3 of emaraviruses $\left(\mathrm{NX}_{2} \mathrm{SXNX}_{3} \mathrm{~A}, \mathrm{NXLA}\right.$, and GYEF) (Elbeaino et al. 2015), PerMV P3a and P3b lacked the first motif (substituted by SILSFSKYSA $94-103$ ), but harbored motifs NRLA $_{138-141}$ and GVEF $_{159-162}$, instead of GYEF (Supplementary Fig. S5).

RNA4 was 1,294 nt in length and contained ORF4 (nucleotide positions 1192 to 161), which encodes P4 of 343 amino acids with a predicted molecular mass of $39.0 \mathrm{kDa}$. P4 showed sequence similarity with those of the other emaraviruses, ranging from 21.6 to $31.1 \%$ (Supplementary Table S4). P4 of RLBV and FMV have been experimentally shown to function as viral MP; localization to plasmodesmata and complementation of a movement-deficient virus (Ishikawa et al. 2013; Yu et al. 2013). In addition, emaravirus $\mathrm{P} 4 \mathrm{~s}$ share elements of a signal peptide, a conserved region called virus $30 \mathrm{~K}$ super domain, and a coiled coil region at the C-terminus (Yu et al. 2013; Zheng et al. 2017). In this analysis, presence of a signal peptide with a cleavage site $\left(\mathrm{ES}_{25} \downarrow_{26} \mathrm{HE}\right)$ was predicted. In an

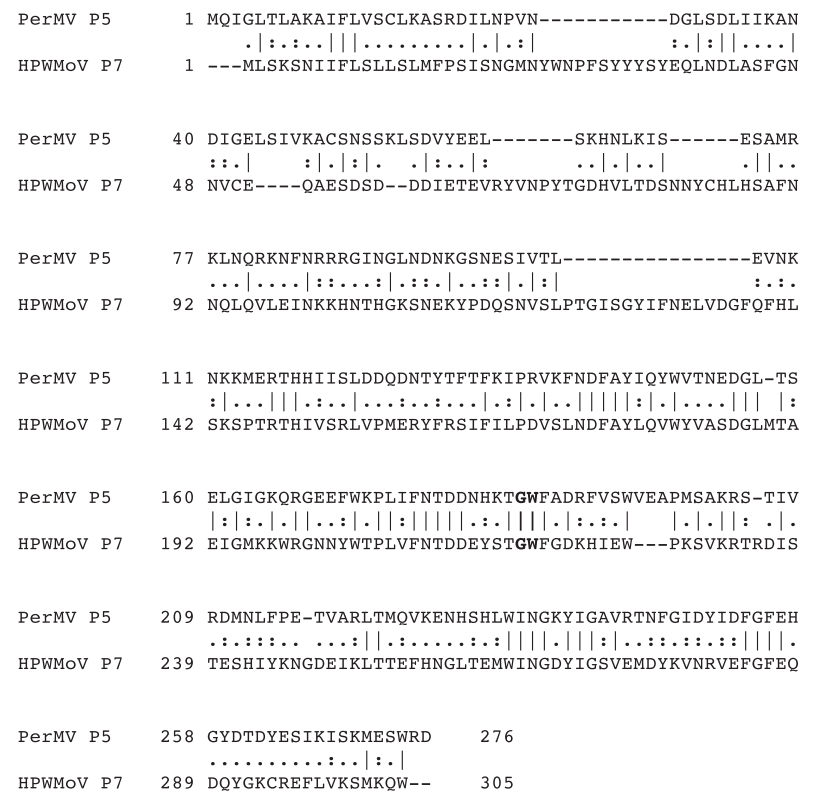

39

47

76

91

Fig. 2. Pairwise amino acid sequence alignment between Perilla mosaic virus (PerMV) P5 and High Plains wheat mosaic virus (HPWMoV) P7, constructed by EMBOSS Needle (Madeira et al. 2019). Amino acid sequence identity and similarity were 27.6 and $44.2 \%$, respectively. The "GW" dipeptide motif conserved in the viral RNA silencing suppressors (Gupta et al. 2019) is shown in bold. amino acid sequence alignment of the P4 of emaraviruses, PerMV $\mathrm{P} 4$ shared residues or motifs that are highly conserved in the $30 \mathrm{~K}$ domain of the other emaraviruses (Kumar et al. 2017; Yu et al. 2013; Zheng et al. 2017) (Supplementary Fig. S6). Among them, the cognate residue of D130 in RLBV P4 has been shown to be indispensable for plasmodesmata localization and rescue of movement-deficient potato virus X (Yu et al. 2013). A coiled coil motif at position 296 to 316 near the C-terminus was predicted but weakly.

RNA5 was 1,066 nt in length, which encoded P5, a 276 amino acid protein of $31.8 \mathrm{kDa}$. PerMV P5 showed sequence similarity with only P7 of HPWMoV (32.7\%), a suppressor of RNA silencing (Gupta et al. 2018). The "GW" dipeptide motif was found in PerMV P5 (Fig. 2), which is conserved among virus RNA silencing suppressors, has been shown to be indispensable for silencing suppression and pathogenicity determination by HPWMoV P7 (Gupta et al. 2019).

RNA6a, RNA6b, and RNA6c were 1,128, 1,097, and 1,050 nt in length and encoded proteins P6a, P6b, and P6c of 29.7, 30.2, and $26.8 \mathrm{kDa}$, respectively. RNA7 was $998 \mathrm{nt}$ in length and encoded protein P7 of 241 amino acids with a predicted molecular mass of $28.5 \mathrm{kDa}$. These four proteins showed no significant sequence similarities to proteins deposited in GenBank. However, P6a, P6b, and P6c showed amino acid sequence similarities to one another. Among them, high amino acid sequence identity of $62.3 \%$ was found between P6a and P6b, whereas P6c showed lower identities of 24.4 and $24.6 \%$ to P6a and P6b, respectively.

Phylogenetic analyses, inferred from amino acid sequence alignment of P1 (RdRp), P2 (GP), P3 (NPs), and P4 (MP) of PerMV and related proteins of emaravirus with selected viruses of the order Bunyavirales as outgroup showed that PerMV is uniquely located compared with the other emaraviruses (Fig. 3). Previously reported emaraviruses segregated into similar clustering of three subgroups (Olmedo-Velarde et al. 2019; Wang et al. 2020). In the NJ trees, P1 and P2 of PerMV segregated together with those of the other emaraviruses with high bootstrap values (100 and 73, respectively) but were basal to the other emaraviruses (Fig. 3A and B). P3a and P3b of PerMV were present in the same clade, and they clustered together with $\mathrm{P} 3 \mathrm{~s}$ of the other emaraviruses. However, the branch was not well supported by bootstrapping (35, not shown) (Fig. 3C). Only PerMV P4 clustered together with the subgroup III of emaraviruses containing TiRSaV (Fig. 3D), which exhibited the highest sequence similarity with PerMV P4 (Supplementary Table S4), but its branch was also not well supported by bootstrapping (49, not shown). These results indicate that PerMV is a distinct and highly divergent species within the genus Emaravirus.

Detection of virion and NPs. Virus particles of emaraviruses consist of genomic RNAs encapsidated by NPs, and virus particles from PerMV-infected shiso leaves were purified. Filamentous virus particles were observed under electron microscopy using the method described in Kumar et al. (2003) (Fig. 4A). An SDS-PAGE and Coomassie blue staining of the purified virion yielded a single band of putative NPs of $\sim 30 \mathrm{kDa}$ (Fig. 4B), which corresponded to the estimated molecular masses of $\mathrm{P} 3 \mathrm{a}$ and $\mathrm{P} 3 \mathrm{~b}$ deduced from amino acid sequences. In the immunoblot analysis of total soluble proteins of leaf samples conducted with an antibody raised against a peptide with sequence common to $\mathrm{P} 3 \mathrm{a}$ and $\mathrm{P} 3 \mathrm{~b}$, a band with the similar molecular mass of $30 \mathrm{kDa}$ was detected specifically from PerMV-infected mosaic leaves (Fig. 4C).

Transmission experiment. Although PRM was assumed to be the vector of PerMV (Kubota 2017; Suzuki et al. 2019), no experimental evidence has been provided. While maintaining PerMV-viruliferous mites, the maintenance plants always became infected with PerMV, suggesting that PRMs transmit the virus. To validate this observation, transmission experiments were conducted. At 7 days posttransfer (DPT), chlorotic spots occasionally appeared on the viruliferous PRM-inoculated leaves, but no 

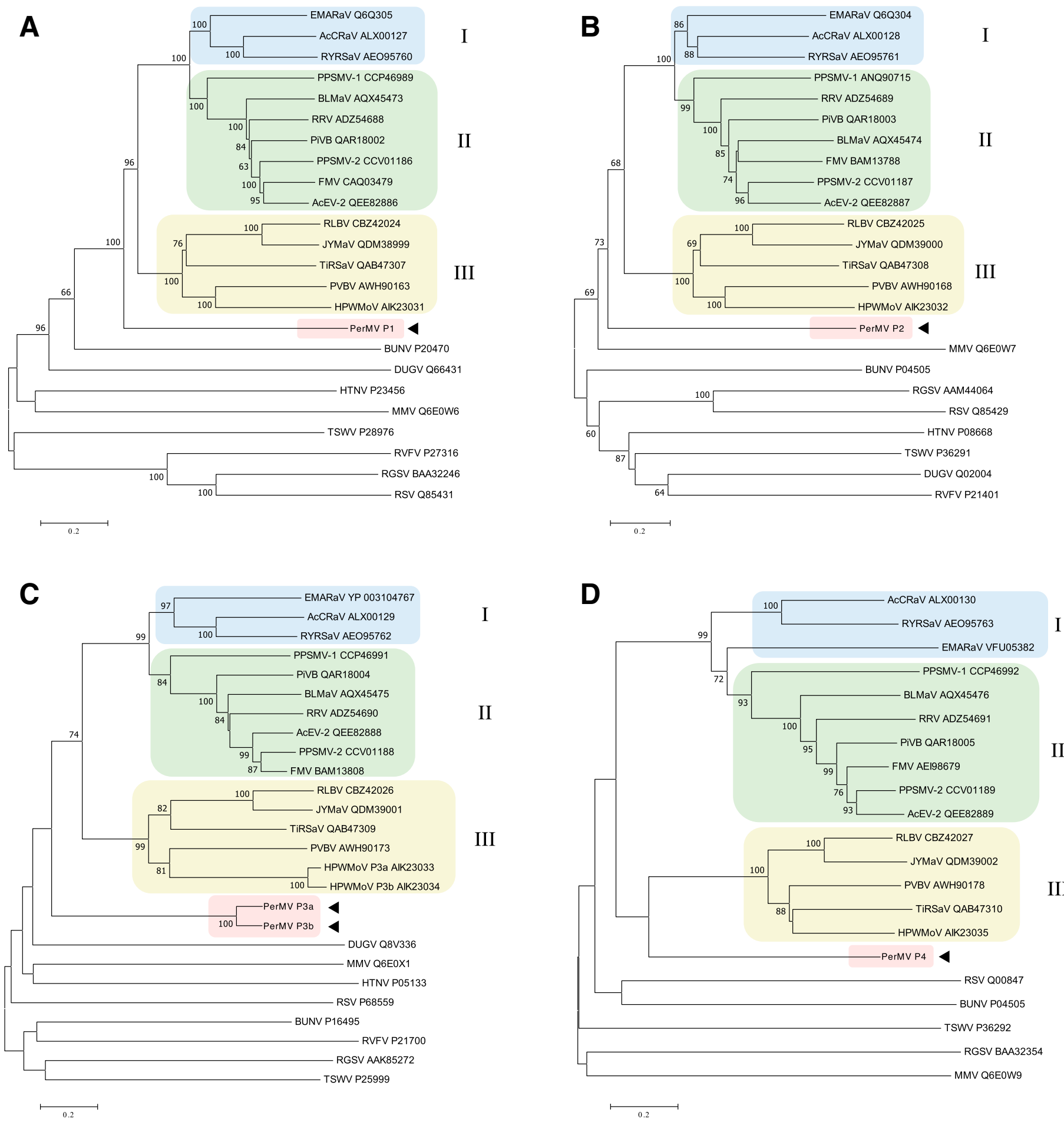

Fig. 3. Phylogenetic relationships of Perilla mosaic virus (PerMV), emaraviruses and selected viruses from the order Bunyavirales. Analyses were performed using the amino acid sequence alignments for the A, RNA-dependent RNA polymerase (RdRp), B, glycoprotein precursor, $\mathbf{C}$, nucleocapsid protein, and $\mathbf{D}$, movement protein. The sequences were aligned by MAFFT version 7 (Katoh and Standley 2013) with default settings. Trees were constructed by using the neighbor joining method provided in the MEGA7 software package (Kumar et al. 2016) and assessed by bootstrapping using 1,000 pseudo-replicates. The numbers at each node represent percentage of the bootstrap values. Those less than $60 \%$ were omitted. The scale bars represent the number of residue substitutions per site. The GenBank accession numbers of the proteins used for phylogenetic analyses are reported. Sequences of maize mosaic virus (MMV), a member of the genus Nucleorabdovirus, the order Mononegavirales were used as outgroup. Viruses of the order Bunyaviridae included are: Bunyamwera virus (BUNV, genus Orthobunyavirus, family Peribunyaviridae), Dugbe virus (DUGV, genus Orthonairovirus, family Nairoviridae), Hantaan virus (HTNV, genus Hantavirus, family Hantaviridae), rice grassy stunt virus (RGSV, genus Tenuivirus, family Phenuiviridae), rice stripe virus (RSV, genus Tenuivirus, family Phenuiviridae), Rift Valley fever virus (RVFV, genus Phlebovirus, family Phenuiviridae), and tomato spotted wilt virus (TSWV, genus Orthotospovirus, family Tospoviridae). Members of the genus Emaravirus include Actinidia chlorotic ringspot-associated virus (AcCRaV); Actinidia emaravirus-2 (AcEV-2); blackberry leaf mottle-associated virus (BLMaV); European mountain ash ringspot-associated virus (EMARaV); fig mosaic virus (FMV); High Plains wheat mosaic virus (HPWMoV); jujube yellow mottle-associated virus (JYMaV); Pistacia virus B (PiVB); blue palo verde broom virus (PVBV); pigeonpea sterility mosaic virus (PPSMV-1); pigeonpea sterility mosaic virus 2 (PPSMV2); raspberry leaf blotch virus (RLBV); rose rosette virus (RRV); redbud yellow ringspot-associated virus (RYRSaV); and ti ringspot-associated virus (TiRSaV). Subgroups of emaraviruses based on the tree for RdRp are surrounded by colored boxes. Proteins of PerMV are indicated by arrowheads. 
symptoms were observed on leaves infested with nonviruliferous PRMs (data not shown). At 14 DPT or after, severe mosaic symptoms, which were indistinguishable by eye from the original

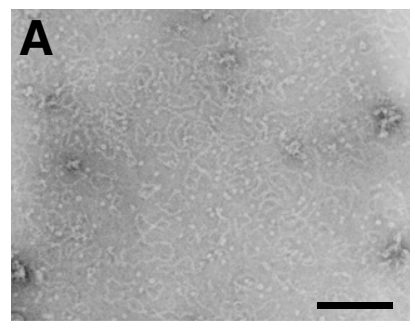

B
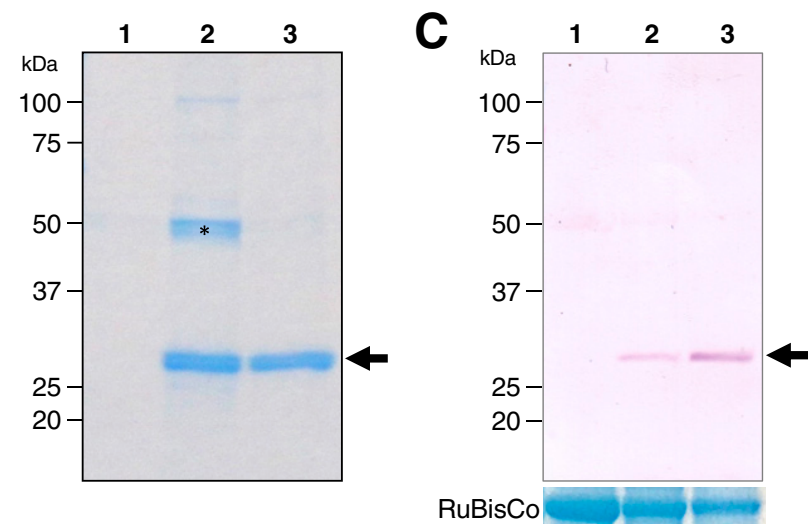

Fig. 4. Detection of virus particles and the nucleocapsid proteins (NPs) of Perilla mosaic virus (PerMV). A, Filamentous virus particles purified from PerMV-infected mosaic leaves. Bar $=200 \mathrm{~nm}$. B, Sodium dodecyl sulfatepolyacrylamide gel electrophoresis analysis of purified virus particles prepared from healthy (lane 1) and mosaic (lanes 2 and 3) leaves of shiso. The band for NPs and traces of RuBisCo large subunit in the preparation are indicated with an arrow and an asterisk, respectively. $\mathbf{C}$, Immunoblot analysis of total soluble proteins extracted from $0.25 \mathrm{mg}$ of healthy (lane 1) and PerMV-infected (lanes 2 and 3 ) shiso leaf tissues. Rabbit antibodies against a peptide with amino acid sequence common to PerMV P3a and P3b were used. The immunoreactive bands detected by alkaline phosphatase conjugated secondary antibodies for putative NPs of PerMV are indicated with an arrow. The bands of RuBisCo protein in the Coomassie brilliant blue-stained gel for estimating the amount of loaded protein are shown at the bottom.

TABLE 1. Results of transmission experiments of Perilla mosaic virus (PerMV) by the perilla rust mite from healthy or PerMV-infected leaf tissue ${ }^{a}$

\begin{tabular}{lcc}
\hline & \multicolumn{2}{c}{$\begin{array}{c}\text { Number of plants positive for } \\
\text { PerMV/number of tested } \\
\text { plants }\end{array}$} \\
\cline { 2 - 3 } Acquisition access period (day) & Healthy $^{\mathrm{c}}$ & PerMV $^{\mathrm{d}}$ \\
\hline 6 & $0 / 4$ & $3 / 4$ \\
12 & $0 / 5$ & $5 / 5$ \\
20 & $0 / 4$ & $4 / 5$ \\
\hline
\end{tabular}

a A shiso plant was exposed to a group of 10 mites for inoculation.

b PerMV infection was evaluated by RT-PCR.

c Healthy, uninfected shiso leaf tissue was used as acquisition source.

d PerMV-infected mosaic leaf tissue was used as acquisition source. ones observed in the shiso fields, developed on plants inoculated with PerMV-acquired PRMs (Supplementary Fig. S1A and D). Infection of PerMV was confirmed by RT-PCR analysis of total RNA extracted from noninoculated upper leaves (Table 1), whereas neither mosaic symptoms nor PerMV infection were observed on plants infested with mites fed on healthy leaves. Transmission was achieved by as short as 30 min of AAP (Table 2). In the transmission experiments with 12 or 18 days of AAPs, vector mites contained young offspring that emerged during AAP. Transovarial transmission of PerMV was not observed in spite of several trials (data not shown). These results clearly demonstrated that PerMV is transmitted by the PRM.

To look for another vector species of PerMV in the field, we tested whether arthropods usually found in shiso production greenhouses could transmit PerMV. During symptom observation of 28 days after IAP, no transmission of the disease was observed from the 10 arthropod species (Supplementary Table S5).

Host range. In Aichi Prefecture from August to September 2013, a field survey was conducted of plants grown in and around eight shiso greenhouses where the mosaic disease caused by PerMV occurred. Among a total of 155 and 31 samples randomly collected from weeds and woody plants, respectively, no PerMV infection was detected by RT-PCR. However, eight naturally grown shiso samples collected at the same time were all infected and some were infested with PRM (K. Kubota, H. Kojima, H. Tanaka, and Y. Kaneko, unpublished data). Because occurrences of PerMV and PRM were confirmed in cultivated egoma as well as cultivated green shiso in Aichi Prefecture, we tested the host range of PerMV in the family Lamiaceae by inoculation with PerMV-viruliferous mites. Systemic infection of PerMV was caused by infestation of PRM, and it induced mosaic symptoms in all of the four species in the genus Perilla (Table 3 and Supplementary Fig. S7). Alternatively, the Lamiaceae species Ajuga decumbens, Clinopodium gracile, and Lamium amplexicaule, often observed in and around shiso greenhouses from autumn to spring, were not infected with PerMV (Table 3). N. benthamiana was infected with PerMV by both mite-borne and mechanical inoculation, and it induced mottle, mosaic, or severe leaf roll (Table 3 and Supplementary Fig. S7E).

\section{DISCUSSION}

Recent advances and spread of NGS technologies have made it easier to identify unknown viruses. In the last decade, over 10 species of emaravirus have been discovered. By using this technique in combination with dsRNA cloning and PCR amplification, we identified a previously unknown emaravirus from shiso plants and determined the complete nucleotide sequences of the segments. Our results altogether establish that PerMV has similar characteristics to emaraviruses in genome organization and protein sequences as well as in biological characteristics, including virion morphology and eriophyid mite-borne transmission. We have also demonstrated that the mosaic disease of shiso is caused by PRMborne PerMV infection, whereas infestation of PRM itself does not cause the disease. To the best of our knowledge, PerMV is also the first validated emaravirus that causes significant economic damage in vegetable crops.

TABLE 2. Results of transmission experiments of Perilla mosaic virus (PerMV) by the perilla rust mite during a short acquisition access period ${ }^{\mathrm{a}}$

\begin{tabular}{|c|c|c|c|c|}
\hline \multirow[b]{2}{*}{ Acquisition access period (hour) } & \multicolumn{3}{|c|}{ Number of plants positive for PerMV/number of tested plants ${ }^{b}$} & \multirow[b]{2}{*}{ Average transmission rate $(\%)$} \\
\hline & Experiment 1 & Experiment 2 & Experiment 3 & \\
\hline 0.5 & $2 / 6$ & $0 / 6$ & $0 / 6$ & 11.1 \\
\hline 1 & $0 / 6$ & $2 / 6$ & $1 / 6$ & 16.7 \\
\hline 2 & $1 / 6$ & $0 / 6$ & $1 / 6$ & 11.1 \\
\hline 4 & $4 / 6$ & $3 / 6$ & $2 / 6$ & 50.0 \\
\hline
\end{tabular}

a A shiso plant was exposed to a group of five mites for inoculation.

b PerMV infection was evaluated by RT-PCR. 
The genome of PerMV consists of 10 RNA segments, which is the highest number of RNA segments reported in known emaraviruses. The segments share characteristics common to those of the other emaraviruses, i.e., (i) there are conserved 11- and 12-nt sequences at the $5^{\prime}$ - and $3^{\prime}$-termini, (ii) $\sim 20 \mathrm{nt}$ of $5^{\prime}$ - and $3^{\prime}$-terminal sequences of each segment showed partial complementarity, and (iii) each RNA segment contained one ORF in the negative-sense orientation (Fig. 1 and Supplementary Fig. S2).

As with all emaraviruses reported, PerMV harbors four RNA segments encoding P1 (RdRp), P2 (GP), P3 (NP), and P4 (MP). Phylogenetic trees inferred with amino acid sequences of P1 to P4 displayed three main clusters consisting of known emaraviruses. The proteins of PerMV, except for P3a and P3b, clustered together with those of the other known emaraviruses, but none of them grouped within the three clusters. The amino acid sequence identities of P1 to P3 of PerMV and those of the other emaraviruses ranged from $19.9 \%$ (P3a) to $33.0 \%$ (P1) (Supplementary Table S4). Following the species demarcation criteria in the genus Emaravirus that amino acid sequence of RdRp, GP, and NP differing by more than 25\% (Elbeaino et al. 2018), PerMV is a distinct species in the genus Emaravirus. As to P3a and P3b of PerMV, they did not cluster with the known emaraviruses (Fig. 3) and lacked or had modified motifs conserved in $\mathrm{P} 3 \mathrm{~s}$ of emaraviruses, suggesting that PerMV is a highly divergent emaravirus.

PerMV P5 showed low sequence similarity to P7 of HPWMoV, which has been reported to be an RNA silencing suppressor with siRNA binding activity (Gupta et al. 2018, 2019). In addition, PerMV P5 also contained the "GW" motif that is indispensable for RNA silencing suppression (Fig. 2). These results suggest that PerMV P5 could be an RNA silencing suppressor. However, no other emaravirus proteins have been reported to be homologous to HPWMoV P7, suggesting a greater diversity of RNA silencing suppressors in emaraviruses.

No homologous proteins to PerMV P6a, P6b, and P6c were found by Pfam database search, which limited inferring their molecular functions. The proteins share amino acid sequence similarities, and such redundancy in encoded proteins of emaraviruses has been also reported in HPWMoV (P5 and P6) (Tatineni et al. 2014), RLBV (P6, P7, and P8) (Lu et al. 2015), RRV (P5 and P7) (Babu et al. 2016; Di Bello et al. 2015), PiVB (P5) (Buzkan et al. 2019), and EMARaV (P4 and P27) (von Bargen et al. 2019). PerMV P7 had no homologous proteins. Because HPWMoV encodes two RNA silencing suppressors, P7 and P8, with different molecular activities (Gupta et al. 2019), it is possible that PerMV encodes two or more suppressor proteins. Additionally, HPWMoV isolates in the United States have considerable genetic variations and form two distinct groups (Stewart 2016). Partial nucleotide sequences of RNA4 of PerMV isolates collected from various locations in Japan also exhibited considerable genetic diversity, and the isolates are also divided into two major subgroups (Suzuki et al. 2019).

Despite several trials of electron microscopy observation of ultrathin sections of infected shiso plants, we could not confirm the presence of the DMB-like particles (data not shown). Based on electron microscopy observations of the purified virions, we detected several filamentous particles of various lengths, which are most likely PerMV nucleoproteins. The SDS-PAGE analysis of purified fractions showed a band with the expected size of PerMV P3a and P3b. In addition, immunoblot analysis of the total soluble proteins of the infected leaves with antibodies specific to a peptide sequence common in PerMV P3a and P3b, protein accumulation of the same size was detected in the PerMV-infected leaves. However, it was impossible to distinguish $\mathrm{P} 3 \mathrm{a}$ and $\mathrm{P} 3 \mathrm{~b}$ because of their very close molecular masses. Furthermore, we did not distinguish whether P3a or P3b or both of them were expressed and constitute the virus particles. Immunoblot analysis or immunoelectron microscopy observations with antibodies specific to $\mathrm{P} 3 \mathrm{a}$ or $\mathrm{P} 3 \mathrm{~b}$ would be necessary. Following HPWMoV and PiVB, PerMV is the third emaravirus that has been reported to possess two RNA segments encoding NPs. Involving two NPs might be a general strategy in infection cycles of at least a subset of emaraviruses.

As reported for other emaraviruses, PerMV has been demonstrated to be transmitted by an eriophyid mite, the PRM (Shevtchenkella sp.) (Table 1). All previously reported vector mites of emaraviruses belonged to the genera Aceria or Phyllocoptes. This is the first report of an emaravirus transmitted by an eriophyid mite of the genus Shevtchenkella, broadening the diversity of emaravirus and vector mite relationships. In combination with a vector mite, A. cajani, PPSMV can be transmitted between pigeon pea plants with a minimum AAP of 15 min, and the transmission rate gradually increases with longer AAPs up to $\sim 24 \mathrm{~h}$ (Kulkarni et al. 2002). Although we did not observe such a clear relationship between AAP and transmission rate of PerMV with the PRM, it was confirmed that transmission of PerMV was achieved in as short an AAP period as $30 \mathrm{~min}$ (Table 2). Symptomatic transmission of the mosaic disease was not observed in any of the other 10 species of arthropods (whiteflies, aphids, leafhoppers, a mealybug, a broad mite, and a thrips) usually found in shiso greenhouses (Supplementary Table S5), though infection of PerMV was not tested by RT-PCR in the inoculated plants. These results indicate that specifically controlling PRM will most likely minimize or prevent occurrences of the mosaic disease caused by PerMV.

Occurrences of the PRM and mosaic disease caused by PerMV have been noted on egoma cultivated in greenhouses (Kubota 2017). Although the purple-leaved shiso can be a host of both PRM and PerMV, significant agricultural damage has yet to be reported, most likely because the purple-leaved shiso is, (i) harvested in June prior to

TABLE 3. Host range of Perilla mosaic virus (PerMV)

\begin{tabular}{|c|c|c|c|c|c|}
\hline Family & Species & Accession $^{\mathrm{a}}$ & Systemic symptom ${ }^{\mathrm{b}}$ & $\begin{array}{c}\text { Number of plants positive for PerMV/ } \\
\text { number of tested plants }{ }^{c}\end{array}$ & Inoculation $^{\mathrm{d}}$ \\
\hline \multirow[t]{8}{*}{ Lamiaceae } & Perilla frutescens var. crispa $^{\mathrm{e}}$ & JP220263 & - & $3 / 5$ & Mites \\
\hline & Perilla frutescens var. frutescens & JP219978 & M & $2 / 4$ & Mites \\
\hline & Perilla citriodora & JP221852 & M & $1 / 1$ & Mites \\
\hline & Perilla hirtella & JP230283 & M & $3 / 6$ & Mites \\
\hline & Perilla setoyensis & JP230284 & M & $2 / 4$ & Mites \\
\hline & Ajuga decumbens & - & - & $0 / 4$ & Mites \\
\hline & Clinopodium gracile & - & - & $0 / 4$ & Mites \\
\hline & Lamium amplexicaule & - & - & $0 / 4$ & Mites \\
\hline \multirow[t]{2}{*}{ Solanaceae } & Nicotiana benthamiana & - & M, LR & $7 / 8$ & Mites \\
\hline & N. benthamiana & - & Mo & $3 / 5$ & Mechanical \\
\hline
\end{tabular}

Vol. 110 , No. 7,2020 
the proliferation season of PRM, (ii) grown mainly in the open field, and (iii) difficult to recognize the mosaic symptoms due to the dark color. However, we often found purple-leaved shiso infested with PRM and infected with PerMV that were artificially or naturally grown in garden fields near shiso greenhouses, suggesting that the purple-leaved shiso can be a potential reservoir of PerMV and the PRM.

The host range experiment results (Table 3 ) also showed that host range of PerMV was relatively narrow, mainly in the genus Perilla, suggesting that the reservoirs of PerMV around the greenhouses may be confined only to shiso and egoma. However, $N$. benthamiana plants experimentally infested with PerMV-viruliferous PRMs were infected with PerMV and exhibited severe, systemic symptoms at a high rate, indicating that the PRMs feed and are able to transmit the virus to even nonhost PRM plants.

In Japan, free growing Perilla plants are usually not able to overwinter, and seed transmission of PerMV in shiso has never been observed (S. Takeuchi, unpublished data). Thus, transmission cycle of PerMV would be mainly achieved through the PRM. In control of the mosaic disease, removing wild or artificially grown shiso or egoma plants around a shiso greenhouse, which are potential reservoirs of RPM, in addition to removal of shiso showing mosaic symptoms in the greenhouse and spraying acaricides, showed great effect, which reduced the occurrence rate from $16 \%$ to less than $1 \%$ (Tsunekawa et al. 2019).

Following FMV on fig trees (Ishikawa et al. 2012b), PerMV is the second emaravirus that has emerged in Japan. Although varieties of Perilla frutescens are widely grown as food and medicinal crops not only in Japan but also in China, Korea, and other countries in Southeast Asia, where PerMV and PRMs originated remains elusive. In Japan, occurrences of PerMV and PRM have been confirmed not only in Kochi but also in Ibaraki, Aichi, and Oita Prefectures. These observations may suggest that PerMV and PRM have not been recently introduced to Perilla plants in Japan. Investigation of the genetic variations in the other PerMV segments as well as PRM populations in different areas of Japan and other countries where Perilla plants are cultivated or endemic may provide further insights.

\section{ACKNOWLEDGMENTS}

We thank T. Fujikawa and Y. Matsushita for supporting NGS analysis; T. Shimoda for technical advice; J. A. Kochiken, the NARO Genebank Project, and M. Asai for providing seeds; and Y. Matsumura, Y. Narita, J. Sato, and M. Tawa for their assistance in preparing biological samples and laboratory work.

\section{LITERATURE CITED}

Altschul, S. F., Madden, T. L., Schäffer, A. A., Zhang, J., Zhang, Z., Miller, W., and Lipman, D. J. 1997. Gapped BLAST and PSI-BLAST: A new generation of protein database search programs. Nucleic Acids Res. 25:3389-3402.

Amrine, J., Hindal, D., Stany, T., Williams, R., and Coffman, C. 1988. Transmission of the rose rosette disease agent to Rosa multiflora Thunb. by Phyllocoptes fructiphilus Keifer (Acari: Eriophyidae). Entomol. News 99: 239-252.

Amroun, A., Priet, S., de Lamballerie, X., and Quérat, G. 2017. Bunyaviridae RdRps: Structure, motifs, and RNA synthesis machinery. Crit. Rev. Microbiol. 43:753-778.

Babu, B., Washburn, B. K., Poduch, K., Knox, G. W., and Paret, M. L. 2016. Identification and characterization of two novel genomic RNA segments RNA5 and RNA6 in rose rosette virus infecting roses. Acta Virol. 60:156-165.

Bendtsen, J. D., Nielsen, H., von Heijne, G., and Brunak, S. 2004. Improved prediction of signal peptides: SignalP 3.0. J. Mol. Biol. 340:783-795.

Buzkan, N., Chiumenti, M., Massart, S., Sarpkaya, K., Karadağ, S., and Minafra, A. 2019. A new Emaravirus discovered in Pistacia from Turkey. Virus Res. 263:159-163.

Di Bello, P. L., Ho, T., and Tzanetakis, I. E. 2015. The evolution of emaraviruses is becoming more complex-Seven segments identified in the causal agent of Rose rosette disease. Virus Res. 210:241-244.
Di Bello, P. L., Laney, A. G., Druciarek, T., Ho, T., Gergerich, R. C., Keller, K. E., Martin, R. R., and Tzanetakis, I. E. 2016. A novel emaravirus is associated with redbud yellow ringspot disease. Virus Res. 222:41-47.

Elbeaino, T., Digiaro, M., Alabdullah, A., De Stradis, A., Minafra, A., Mielke, N., Castellano, M. A., and Martelli, G. P. 2009a. A multipartite singlestranded negative-sense RNA virus is the putative agent of fig mosaic disease. J. Gen. Virol. 90:1281-1288.

Elbeaino, T., Digiaro, M., and Martelli, G. P. 2009b. Complete nucleotide sequence of four RNA segments of fig mosaic virus. Arch. Virol. 154: 1719-1727.

Elbeaino, T., Digiaro, M., Mielke-Ehret, N., Muehlbach, H. P., and Martelli, G. P. 2018. ICTV virus taxonomy profile: Fimoviridae. J. Gen. Virol. 99: 1478-1479.

Elbeaino, T., Digiaro, M., Uppala, M., and Sudini, H. 2014. Deep sequencing of pigeonpea sterility mosaic virus discloses five RNA segments related to emaraviruses. Virus Res. 188:27-31.

Elbeaino, T., Digiaro, M., Uppala, M., and Sudini, H. 2015. Deep sequencing of dsRNAs recovered from mosaic-diseased pigeonpea reveals the presence of a novel emaravirus: Pigeonpea sterility mosaic virus 2 . Arch. Virol. 160: 2019-2029.

Finn, R. D., Bateman, A., Clements, J., Coggill, P., Eberhardt, R. Y., Eddy, S. R., Heger, A., Hetherington, K., Holm, L., Mistry, J., Sonnhammer, E. L., Tate, J., and Punta, M. 2014. Pfam: The protein families database. Nucleic Acids Res. 42:D222-D230.

Flock, R. A., and Wallace, J. M. 1955. Transmission of fig mosaic by the eriophyid mite Aceria ficus. Phytopathology 45:52-54.

Gambino, G., Perrone, I., and Gribaudo, I. 2008. A rapid and effective method for RNA extraction from different tissues of grapevine and other woody plants. Phytochem. Anal. 19:520-525.

Gordon, S. C., and Taylor, C. E. 1976. Some aspects of the biology of the raspberry leaf and bud mite (Phyllocoptes (Eriophyes) gracilis Nal.) Eriophyidae in Scotland. J. Hortic. Sci. 51:501-508.

Gupta, A. K., Hein, G. L., Graybosch, R. A., and Tatineni, S. 2018. Octapartite negative-sense RNA genome of High Plains wheat mosaic virus encodes two suppressors of RNA silencing. Virology 518:152-162.

Gupta, A. K., Hein, G. L., and Tatineni, S. 2019. P7 and P8 proteins of High Plains wheat mosaic virus, a negative-strand RNA virus, employ distinct mechanisms of RNA silencing suppression. Virology 535:20-31.

Hassan, M., DiBello, P. L., Keller, K. E., Martin, R. R., Sabanadzovic, S., and Tzanetakis, I. E. 2017. A new, widespread emaravirus discovered in blackberry. Virus Res. 235:1-5.

Horikawa, H., Ito, R., Ohashi, H., Tsunekawa, K., Ichikawa, K., Kato, S., and Miyake, N. 2018. Seasonal prevalence of shiso rust mite and shiso mosaic disease on perilla. Annu. Rep. Kansai Plant Prot. 60:23-29 (in Japanese with English abstract).

Ilyas, M., Avelar, S., Schuch, U. K., and Brown, J. K. 2018. First report of an emaravirus associated with witches' broom disease and eriophyid mite infestations of the blue palo verde tree in Arizona. Plant Dis. 102: 1863.

Ishikawa, K., Maejima, K., Komatsu, K., Kitazawa, Y., Hashimoto, M., Takata, D., Yamaji, Y., and Namba, S. 2012a. Identification and characterization of two novel genomic RNA segments of fig mosaic virus, RNA5 and RNA6. J. Gen. Virol. 93:1612-1619.

Ishikawa, K., Maejima, K., Komatsu, K., Netsu, O., Keima, T., Shiraishi, T., Okano, Y., Hashimoto, M., Yamaji, Y., and Namba, S. 2013. Fig mosaic emaravirus p4 protein is involved in cell-to-cell movement. J. Gen. Virol. 94:682-686.

Ishikawa, K., Maejima, K., Nagashima, S., Sawamura, N., Takinami, Y., Komatsu, K., Hashimoto, M., Yamaji, Y., Yamamoto, J., and Namba, S. 2012b. First report of fig mosaic virus infecting common fig (Ficus carica) in Japan. J. Gen. Plant Pathol. 78:136-139.

Ito, M., and Honda, G. 1996. A taxonomic study of Japanese wild Perilla (Labiatae). J. Phytogeogr. Taxon. 44:43-52.

Katoh, K., and Standley, D. M. 2013. MAFFT Multiple Sequence Alignment Software Version 7: Improvements in performance and usability. Mol. Biol. Evol. 30:772-780.

Kobayashi, K., Tomita, R., and Sakamoto, M. 2009. Recombinant plant dsRNA-binding protein as an effective tool for the isolation of viral replicative form dsRNA and universal detection of RNA viruses. J. Gen. Plant Pathol. 75:87-91.

Krogh, A., Larsson, B., von Heijne, G., and Sonnhammer, E. L. L. 2001. Predicting transmembrane protein topology with a hidden Markov model: Application to complete genomes. J. Mol. Biol. 305:567-580.

Kubota, K. 2017. Emergence of emaraviruses, the eriophyoid mite-transmitted viruses in plants. Uirusu 67:37-48 (in Japanese with English abstract).

Kulkarni, N. K., Kumar, P. L., Muniyappa, V., Jones, A. T., and Reddy, D. V. R. 2002. Transmission of Pigeon pea sterility mosaic virus by the eriophyid mite, Aceria cajani (Acari: Arthropoda). Plant Dis. 86: 1297-1302. 
Kumar, P. L., Jones, A. T., and Reddy, D. V. R. 2003. A novel mite-transmitted virus with a divided RNA genome closely associated with pigeonpea sterility mosaic disease. Phytopathology 93:71-81.

Kumar, S., Stecher, G., and Tamura, K. 2016. MEGA7: Molecular evolutionary genetics analysis version 7.0 for bigger datasets. Mol. Biol. Evol. 33:1870-1874

Kumar, S., Subbarao, B. L., and Hallan, V. 2017. Molecular characterization of emaraviruses associated with Pigeonpea sterility mosaic disease. Sci. Rep. 7:11831.

Laney, A. G., Keller, K. E., Martin, R. R., and Tzanetakis, I. E. 2011. A discovery 70 years in the making: Characterization of the rose rosette virus. J. Gen. Virol. 92:1727-1732.

Lee, J. T., Yamashita, S., Doi, Y., and Yora, K. 1980. A potyvirus found in mosaic plants of perilla. Jpn. J. Phytopathol. 46:672-676 (in Japanese with English abstract).

Lu, Y., McGavin, W., Cock, P. J. A., Schnettler, E., Yan, F., Chen, J., and MacFarlane, S. 2015. Newly identified RNAs of raspberry leaf blotch virus encoding a related group of proteins. J. Gen. Virol. 96:3432-3439.

Lupas, A., Van Dyke, M., and Stock, J. 1991. Predicting coiled coils from protein sequences. Science 252:1162-1164.

Madeira, F., Park, Y. M., Lee, J., Buso, N., Gur, T., Madhusoodanan, N., Basutkar, P., Tivey, A. R. N., Potter, S. C., Finn, R. D., and Lopez, R. 2019. The EMBL-EBI search and sequence analysis tools APIs in 2019. Nucleic Acids Res. 47:W636-W641.

Martelli, G. P., Castellano, M. A., and Lafortezza, R. 1993. An ultrastructural study of fig mosaic. Phytopathol. Mediterr. 32:33-43.

McGavin, W. J., Mitchell, C., Cock, P. J. A., Wright, K. M., and MacFarlane, S. A. 2012. Raspberry leaf blotch virus, a putative new member of the genus Emaravirus, encodes a novel genomic RNA. J. Gen. Virol. 93:430-437.

Mielke, N., and Mühlbach, H. P. 2007. A novel, multipartite, negative-strand RNA virus is associated with the ringspot disease of European mountain ash (Sorbus aucuparia L.). J. Gen. Virol. 88:1337-1346.

Mielke-Ehret, N., and Mühlbach, H. P. 2012. Emaravirus: A novel genus of multipartite, negative strand RNA plant viruses. Viruses 4:1515-1536.

Mielke-Ehret, N., Thoma, J., Schlatermund, N., and Mühlbach, H. P. 2010. Detection of European mountain ash ringspot-associated virus-specific RNA and protein P3 in the pear leaf blister mite Phytoptus pyri (Eriophyidae). Arch. Virol. 155:987-991.

Ministry of Agriculture, Forestry and Fisheries of Japan. 2019. Statistical survey on minor crops. https://www.maff.go.jp/j/tokei/kouhyou/tokusan_ yasai/

Muhire, B. M., Varsani, A., and Martin, D. P. 2014. SDT: A virus classification tool based on pairwise sequence alignment and identity calculation. PLoS One 9:e108277.

Olmedo-Velarde, A., Park, A. C., Sugano, J., Uchida, J. Y., Kawate, M., Borth, W. B., Hu, J. S., and Melzer, M. J. 2019. Characterization of ti ringspotassociated virus, a novel emaravirus associated with an emerging ringspot disease of Cordyline fruticosa. Plant Dis. 103:2345-2352.

Pei, J., and Grishin, N. V. 2007. PROMALS: Towards accurate multiple sequence alignments of distantly related proteins. Bioinformatics 23:802-808.

Seifers, D. L., Harvey, T. L., Martin, T. J., and Jensen, S. G. 1997. Identification of the wheat curl mite as the vector of the High Plains virus of corn and wheat. Plant Dis. 81:1161-1166.
Seth, M. L. 1962. Transmission of pigeon-pea sterility by an eriophyid mite. Indian Phytopathol. 15:225-227.

Shimomoto, Y., Kobayashi, K., and Okuda, M. 2014. Identification and characterization of Lisianthus necrotic ringspot virus, a novel distinct tospovirus species causing necrotic disease of lisianthus (Eustoma grandiflorum). J. Gen. Plant Pathol. 80:169-175.

Skare, J. M., Wijkamp, I., Rezende, J., Michels, G., Rush, C., Scholthof, K. B., and Scholthof, H. B. 2003. Colony establishment and maintenance of the eriophyid wheat curl mite Aceria tosichella for controlled transmission studies on a new virus-like pathogen. J. Virol. Methods 108:133-137.

Stewart, L. R. 2016. Sequence diversity of wheat mosaic virus isolates. Virus Res. 213:299-303.

Suzuki, R., Horikawa, H., Tsunekawa, K., and Kubota, K. 2019. Diagnosis of shiso mosaic disease using a reverse transcription loop-mediated isothermal amplification assay. Annu. Rep. Kansai Plant Prot. Soc. 61:31-35 (in Japanese with English abstract).

Suzuki, T., Kadono, F., Kagiwada, S., and Tatara, A. 2018. Overwintering ecology and reproductive diapause condition of Shevtchenkella sp. (Acari: Eriophyidae). Annu. Rep. Kanto-Tosan Plant Prot. Soc. 65:125-129 (in Japanese with English abstract).

Takei, M., Nakahira, T., Okada, T., Kagiwada, S., and Kadono, F. 2019. Ecological characteristics of the perilla rust mite, Shevtchenkella sp., a serious pest species of Perilla frutescens. J. Acarol. Soc. Jpn. 28:1-16 (in Japanese with English abstract).

Tatineni, S., McMechan, A. J., Wosula, E. N., Wegulo, S. N., Graybosch, R. A., French, R., and Hein, G. L. 2014. An eriophyid mite-transmitted plant virus contains eight genomic RNA segments with unusual heterogeneity in the nucleocapsid protein. J. Virol. 88:11834-11845.

Tsunekawa, K., Horikawa, H., Ichikawa, K., Takeyama, K., Suzuki, R., Ohashi, H., Ito, R., Tanaka, H., and Saka, N. 2019. Report on the occurrence of shiso mosaic disease and on-farm research for efficient disease control in the Aichi Prefecture. Annu. Rept. Kansai Plant Prot. Soc. 61:91-98 (in Japanese with English abstract).

von Bargen, S., Dieckmann, H. L., Candresse, T., Mühlbach, H. P., Roßbach, J., and Büttner, C. 2019. Determination of the complete genome sequence of European mountain ash ringspot-associated emaravirus from Sorbus intermedia reveals two additional genome segments. Arch. Virol. 164: 1937-1941.

Wang, Y., Zhai, L., Wen, S., Yang, Z., Wang, G., and Hong, N. 2020. Molecular characterization of a novel emaravrius infecting Actinidia spp. in China. Virus Res. 275:197736.

Yang, C., Zhang, S., Han, T., Fu, J., Di Serio, F., and Cao, M. 2019. Identification and characterization of a novel emaravirus associated with jujube (Ziziphus jujuba Mill.) yellow mottle disease. Front. Microbiol. 10: 1417.

Yu, C., Karlin, D. G., Lu, Y., Wright, K., Chen, J., and MacFarlane, S. 2013. Experimental and bioinformatic evidence that raspberry leaf blotch emaravirus P4 is a movement protein of the $30 \mathrm{~K}$ superfamily. J. Gen. Virol. 94: 2117-2128.

Zheng, Y., Navarro, B., Wang, G., Wang, Y., Yang, Z., Xu, W., Zhu, C., Wang, L., Di Serio, F. D., and Hong, N. 2017. Actinidia chlorotic ringspotassociated virus: A novel emaravirus infecting kiwifruit plants. Mol. Plant Pathol. 18:569-581. 